\title{
The Impact of Changes in InFeed Rate on Surface Integrity after Chrome Plate Grinding by Microcrystalline Corundum
}

Martin Marek, Martin Novák, Karel Šramhauser

Faculty of Mechanical Engineering, J. E. Purkyně University in Usti nad Labem, Pasteurova 3334/7, 40001 Ústí nad Labem.Email: martin.marek@ujep.cz, martin.novak1@ujep.cz,karel.sramhauser@ujep.cz

The efficient processing of materials, the development of machine concepts and grinding tools, as well as growing environmental and economic pressure are existing challenges in grinding. Chromium coatings are mainly used for components where corrosion protection is required, but also for the repair of worn parts. This paper presents and discusses the possibilities of utilizing changes in feed rate to achieve guaranteed surface integrity, which is very important for the life of the component. The results are presented in the form of tables and graphs, where I focus mainly on parameters of surface roughness and circularity.

Keywords: grinding, surface integrity, cutting conditions, hard chrome coating

\section{Introduction}

Grinding is an abrasive cutting process for producing accurate dimensions and cuts on various materials. This process is one of the most used for finishing operations, but also can help in mass production that requires removing large amounts of roughed out material. Grinding is a characteristic process that is influenced by several factors: large cutting forces, the generation of a large amount of heat due to irregularities of the grinding wheel, irregular chip removal, irregular geometry of the cutting edge, a small cross-section of the chip, self-sharpening of the grinding wheel, high cut rates (typically $35 \mathrm{~m} . \mathrm{s}^{-1}$, sometimes above $100 \mathrm{~m} \cdot \mathrm{s}^{-1}$ ), residual stresses, the amount of deformation in the areas of primary and secondary deformation, and in the area of contact of the tool with the machined surface, cutting environment and more.[1-6]

In a wide range, surface integrity can be separated into two aspects: the internal subsurface layers of microstructure, mechanical properties and residual stresses and of external topography of surfaces (surface finish). Experts in the field around the world have gathered together research on surface integrity after grinding. Topics enclosed include: surface topography evaluation and characterization, the definition of surface integrity, the mechanical properties of subsurface layers and microstructure modification, residual stresses, surface integrity aspects in machining processes and surface integrity characterization methods, etc. [7-10]

Hard chrome plating is a significant surface treatment of nominated mechanical components, which significantly increases the life of individual parts. The quality of chrome plating depends on the selection of the right technological process. Chromium coatings are mainly used for components where corrosion protection is required. In this case, the chrome coating is applied due to increased surface hardness, abrasion resistance and high temperature resistance. For this experiment, the chromium process was chosen because of its widespread use in refurbishing parts after dismantling gas turbines and subsequently assembling them. [11-16]

The aim of this research was to find optimal cutting conditions when grinding wheels based on microcrystalline corundum were used, where the main consideration in measurement and evaluation was circularity and roughness of the surface and its profile after grinding. This experiment was in cooperation with Solar Turbines EAME L.t.d.

\section{Plan of experiment and cutting conditions}

The aim of this experiment was grinding chrome platied rings (Fig. 1).

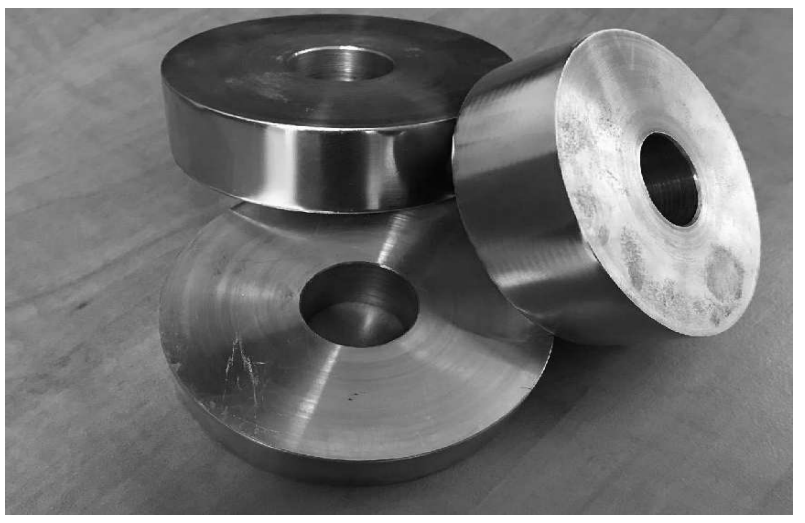

Fig. 1 Example of pattern

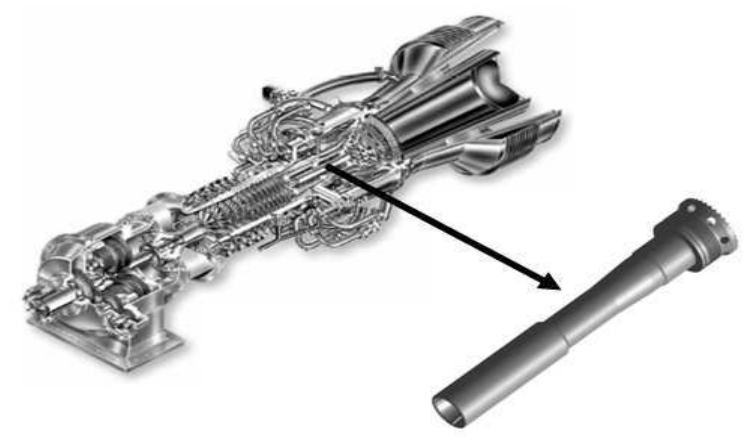

Fig. 2 A sample of the shaft from the combustion part of the turbine which has been cut

These rings were cut at the frame saw mill. The next operation for preparation of samples was machining the 
heads of samples and the drilled inner diameter. The last operation was galvanic plating with chromium, where the thicknes was around $0.4 \mathrm{~mm}$. The base material was chrome-nickel-molybdate steel (shaft - Fig. 2), which corresponds with AMS 6415.

In Tab. 1 it is possible to see the chemical composition of the base material, which was analysed by Q4 TASMAN optical emission spectrometer (Fig. 3). All values are supplemented by a standard deviation.

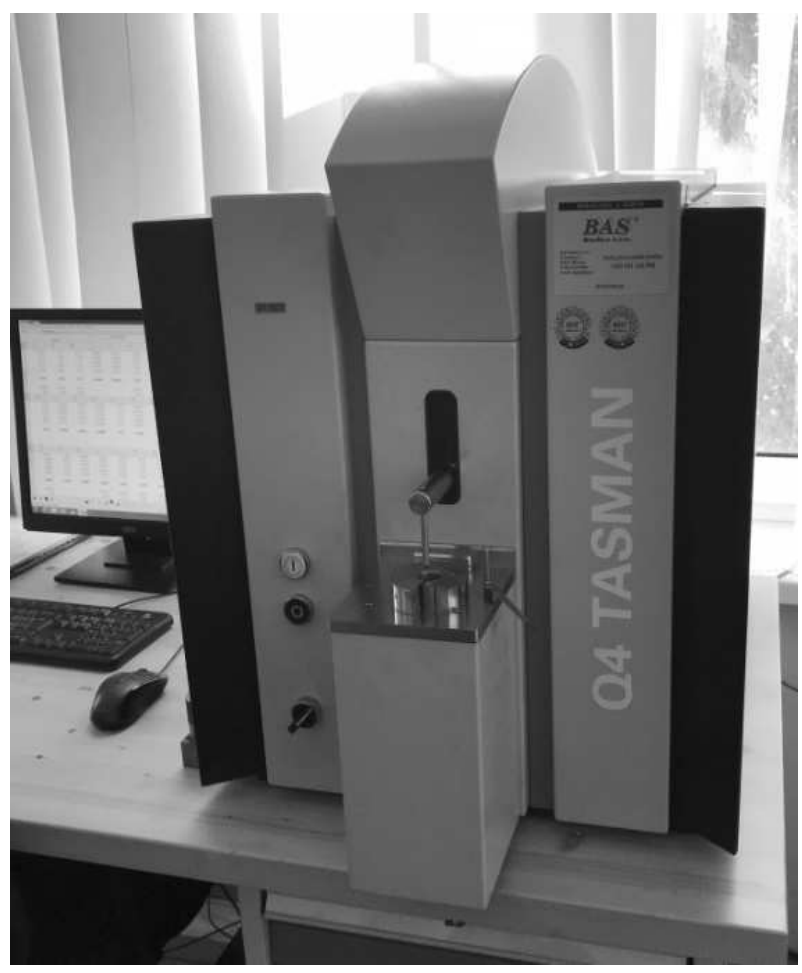

Fig. 3 Q4 TASMAN optical emission spectrometer

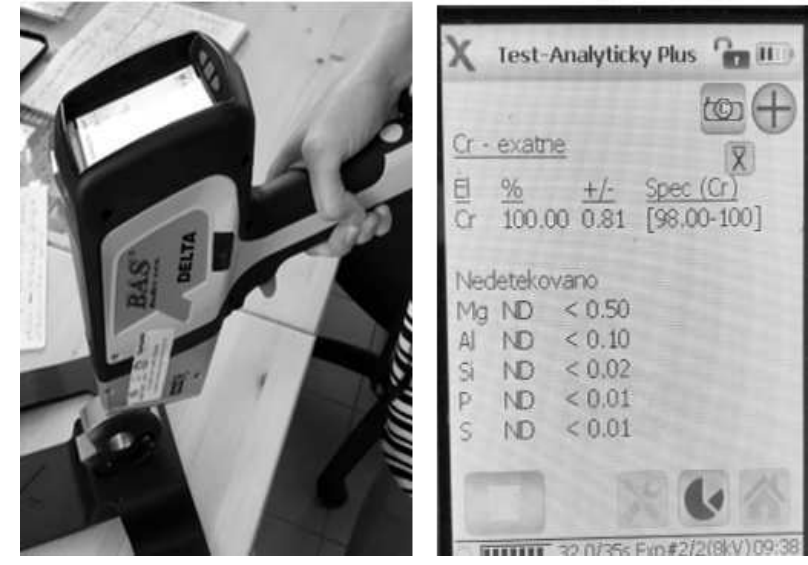

Fig. 4 DELTA optical spectrometry and chemical composition of chromium layer

For verification of the galvanic chromium layer, the analysis was carried out using the DELTA Handheld Optical Spectrometer (Fig. 4). It can be seen from the figure that the chemical composition of the galvanized layer is almost $100 \%$ chromium.

Hakufluid 182 procedural fluid was used for the experiment. This process liquid is water-based with a $4-7$ $\%$ concentration and was chosen based on previous experiments. For grinding, the AG 92/99 150J 9V grinding tool was chosen, which is characterized by high hardness, porous structure, moderate grain size and a ceramic binder. The grains of the grinding wheel show a higher material removal rate and a lower number of dressing cycles. The selected grinding wheel has a maximum permissible circumferential velocity of $40 \mathrm{~m} . \mathrm{s}-1$. A $0.1 \mathrm{~mm}$ depth removal rate was chosen. All cutting conditions are shown in Tab. 2.

Tab. 1 Chemical composition

\begin{tabular}{|c|c|c|c|c|c|c|c|c|c|c|}
\cline { 2 - 11 } \multicolumn{1}{c|}{} & \multicolumn{8}{c|}{ Chemical composition of base material [hm. \%] } \\
\hline Element & $\mathbf{C}$ & $\mathbf{M n}$ & $\mathbf{P}$ & $\mathbf{C r}$ & $\mathbf{M o}$ & $\mathbf{S}$ & $\mathbf{N i}$ & $\mathbf{S i}$ & $\mathbf{F e}$ \\
\hline $\boldsymbol{\%}$ & 0.415 & 0.711 & $<0.005$ & 0.817 & 0.234 & $<0.001$ & 1.835 & 0.263 & 95.300 \\
\hline$\pm \boldsymbol{\sigma}$ & 0.004 & 0.004 & - & 0.003 & 0.001 & - & 0.008 & 0.003 & 0.010 \\
\hline
\end{tabular}

Tab. 2 Cutting condition

\begin{tabular}{|c|c|c|c|c|c|}
\hline \multirow{2}{*}{ Material } & \multirow{2}{*}{ Grinding wheel } & \multicolumn{3}{|c|}{ Cutting conditions } & \multirow{2}{*}{ No. sample } \\
\hline & & $\mathbf{V w}$ & Ve & Vf & \\
\hline \multirow{10}{*}{$\begin{array}{c}\text { Galvanic } \\
\text { Chrome } \\
\text { plate }\end{array}$} & \multirow{10}{*}{ AG 92/99 150J 9V } & \multirow{10}{*}{$15 \mathrm{~m} \cdot \mathrm{min}^{-1}$} & \multirow{5}{*}{$30 \mathrm{~m} \cdot \mathrm{s}^{-1}$} & $0.13 \mathrm{~mm} \cdot \mathrm{min}^{-1}$ & A1 \\
\hline & & & & $0.17 \mathrm{~mm} \cdot \mathrm{min}^{-1}$ & $\mathrm{~A} 2$ \\
\hline & & & & $0.26 \mathrm{~mm} \cdot \mathrm{min}^{-1}$ & A3 \\
\hline & & & & $0.41 \mathrm{~mm} \cdot \mathrm{min}^{-1}$ & A4 \\
\hline & & & & $0.64 \mathrm{~mm} \cdot \mathrm{min}^{-1}$ & A5 \\
\hline & & & \multirow{5}{*}{$40 \mathrm{~m} \cdot \mathrm{s}^{-1}$} & $0.13 \mathrm{~mm} \cdot \mathrm{min}^{-1}$ & A6 \\
\hline & & & & $0.17 \mathrm{~mm} \cdot \mathrm{min}^{-1}$ & A7 \\
\hline & & & & $0.26 \mathrm{~mm} \cdot \mathrm{min}^{-1}$ & A8 \\
\hline & & & & $0.41 \mathrm{~mm} \cdot \mathrm{min}^{-1}$ & A9 \\
\hline & & & & $0.64 \mathrm{~mm} \cdot \mathrm{min}^{-1}$ & A10 \\
\hline
\end{tabular}


The surface roughness and its profile were measured using the T8000 Hommel Tester. which measures the surface according to the CSN EN ISO 4287 standard. Each sample was measured $12 \mathrm{x}$ at $30^{\circ}$ to obtain values along the entire circumference. For surface roughness I worked with parameters such as Ra. Rz. Rt. Rq. Rmax. Rpk and
Rvk. I was also dealing with characteristics of the material and surface profile. From all 12 values for each sample the arithmetic mean was calculated and supplemented by a standard deviation. Surface roughness values are shown in Table 3.

Tab. 3 Average values of surface roughness

\begin{tabular}{|c|c|c|c|c|c|c|c|c|}
\hline $\begin{array}{c}\text { No } \\
\text { sample }\end{array}$ & & $\begin{array}{c}\mathbf{R a} \\
{[\mu \mathrm{m}]}\end{array}$ & $\begin{array}{c}\mathbf{R z} \\
{[\mu \mathrm{m}]}\end{array}$ & $\begin{array}{c}\text { Rt } \\
{[\mu \mathrm{m}]}\end{array}$ & $\begin{array}{c}\operatorname{Rmax} \\
{[\mu \mathrm{m}]}\end{array}$ & $\begin{array}{c}\text { Rpk } \\
{[\mu \mathrm{m}]}\end{array}$ & $\begin{array}{c}\text { Rvk } \\
{[\mu \mathrm{m}]}\end{array}$ & $\begin{array}{c}\mathbf{R q} \\
{[\mu \mathbf{m}]}\end{array}$ \\
\hline \multirow{2}{*}{ A1_1 } & Arithmetic Average & 0.194 & 1.418 & 1.730 & 1.664 & 0.213 & 0.335 & 0.245 \\
\hline & Standart Deviation & 0.007 & 0.061 & 0.138 & 0.163 & 0.024 & 0.026 & 0.009 \\
\hline \multirow{2}{*}{ A1_2 } & Arithmetic Average & 0.176 & 1.287 & 1.618 & 1.537 & 0.198 & 0.267 & 0.22 \\
\hline & Standart Deviation & 0.011 & 0.085 & 0.248 & 0.231 & 0.018 & 0.02 & 0.013 \\
\hline \multirow{2}{*}{ A2_1 } & Arithmetic Average & 0.236 & 1.657 & 2.077 & 2.037 & 0.271 & 0.346 & 0.296 \\
\hline & Standart Deviation & 0.01 & 0.096 & 0.209 & 0.173 & 0.029 & 0.028 & 0.013 \\
\hline \multirow{2}{*}{ A2_2 } & Arithmetic Average & 0.238 & 1.603 & 1.963 & 1.920 & 0.258 & 0.313 & 0.295 \\
\hline & Standart Deviation & 0.007 & 0.071 & 0.198 & 0.229 & 0.023 & 0.046 & 0.008 \\
\hline \multirow{2}{*}{ A3_1 } & Arithmetic Average & 0.258 & 1.791 & 2.273 & 2.138 & 0.275 & 0.378 & 0.323 \\
\hline & Standart Deviation & 0.006 & 0.056 & 0.182 & 0.140 & 0.048 & 0.033 & 0.008 \\
\hline \multirow{2}{*}{ A3_2 } & Arithmetic Average & 0.274 & 1.939 & 2.363 & 2.218 & 0.339 & 0.371 & 0.344 \\
\hline & Standart Deviation & 0.007 & 0.116 & 0.231 & 0.169 & 0.018 & 0.025 & 0.008 \\
\hline \multirow{2}{*}{ A4_1 } & Arithmetic Average & 0.297 & 2.050 & 2.50 & 2.382 & 0.334 & 0.427 & 0.373 \\
\hline & Standart Deviation & 0.011 & 0.165 & 0.351 & 0.215 & 0.046 & 0.056 & 0.016 \\
\hline \multirow{2}{*}{ A4_2 } & Arithmetic Average & 0.297 & 2.187 & 2.641 & 2.503 & 0.363 & 0.486 & 0.378 \\
\hline & Standart Deviation & 0.01 & 0.125 & 0.262 & 0.229 & 0.051 & 0.052 & 0.015 \\
\hline \multirow{2}{*}{ A5_1 } & Arithmetic Average & 0.337 & 2.392 & 2.943 & 2.825 & 0.401 & 0.519 & 0.424 \\
\hline & Standart Deviation & 0.015 & 0.132 & 0.225 & 0.169 & 0.031 & 0.045 & 0.017 \\
\hline \multirow{2}{*}{ A5_2 } & Arithmetic Average & 0.331 & 2.368 & 2.864 & 2.731 & 0.400 & 0.506 & 0.417 \\
\hline & Standart Deviation & 0.010 & 0.135 & 0.244 & 0.206 & 0.043 & 0.062 & 0.014 \\
\hline \multirow{2}{*}{ A6_1 } & Arithmetic Average & 0.271 & 1.811 & 2.152 & 2.077 & 0.262 & 0.417 & 0.336 \\
\hline & Standart Deviation & 0.009 & 0.086 & 0.23 & 0.173 & 0.026 & 0.046 & 0.011 \\
\hline \multirow{2}{*}{ A6_2 } & Arithmetic Average & 0.268 & 1.952 & 2.387 & 2.297 & 0.307 & 0.44 & 0.339 \\
\hline & Standart Deviation & 0.015 & 0.183 & 0.259 & 0.231 & 0.031 & 0.073 & 0.02 \\
\hline \multirow{2}{*}{ A7_1 } & Arithmetic Average & 0.292 & 2.021 & 2.435 & 2.297 & 0.341 & 0.379 & 0.365 \\
\hline & Standart Deviation & 0.008 & 0.124 & 0.306 & 0.320 & 0.039 & 0.045 & 0.012 \\
\hline \multirow{2}{*}{ A7_2 } & Arithmetic Average & 0.298 & 2.075 & 2.486 & 2.395 & 0.322 & 0.543 & 0.377 \\
\hline & Standart Deviation & 0.008 & 0.092 & 0.163 & 0.144 & 0.02 & 0.052 & 0.009 \\
\hline \multirow{2}{*}{ A8_1 } & Arithmetic Average & 0.301 & 1.986 & 2.354 & 2.255 & 0.321 & 0.487 & 0.377 \\
\hline & Standart Deviation & 0.011 & 0.09 & 0.127 & 0.157 & 0.034 & 0.076 & 0.013 \\
\hline \multirow{2}{*}{ A8_2 } & Arithmetic Average & 0.304 & 2.143 & 2.584 & 2.505 & 0.376 & 0.432 & 0.383 \\
\hline & Standart Deviation & 0.006 & 0.08 & 0.235 & 0.223 & 0.042 & 0.025 & 0.007 \\
\hline \multirow{2}{*}{ A9_1 } & Arithmetic Average & 0.323 & 2.167 & 2.598 & 2.475 & 0.289 & 0.524 & 0.402 \\
\hline & Standart Deviation & 0.008 & 0.115 & 0.227 & 0.166 & 0.032 & 0.061 & 0.009 \\
\hline \multirow{2}{*}{ A9_2 } & Arithmetic Average & 0.315 & 2.401 & 3.099 & 2.92 & 0.384 & 0.555 & 0.402 \\
\hline & Standart Deviation & 0.020 & 0.130 & 0.292 & 0.296 & 0.054 & 0.079 & 0.027 \\
\hline \multirow{2}{*}{ A10_1 } & Arithmetic Average & 0.361 & 2.517 & 2.997 & 2.877 & 0.443 & 0.533 & 0.453 \\
\hline & Standart Deviation & 0.011 & 0.127 & 0.19 & 0.235 & 0.035 & 0.051 & 0.014 \\
\hline \multirow{2}{*}{ A10_2 } & Arithmetic Average & 0.363 & 2.481 & 3.14 & 3.079 & 0.385 & 0.552 & 0.454 \\
\hline & Standart Deviation & 0.015 & 0.148 & 0.365 & 0.400 & 0.043 & 0.105 & 0.019 \\
\hline
\end{tabular}

Circularity measurements were performed on the T4004 Hommel Tester Form according to CSN EN ISO 4298. The circularity indicator is often used in practice for the examination of precisely machined circular parts where the desired tolerance is compared. Measurement was done 3 times. Once in the middle and on each edge of the sample. From the measured values I calculated the arithmetic mean and the standard deviation. Circular values are in Table 4. 
Tab. 4 Average values of circularity

\begin{tabular}{|c|c|c|c|c|c|c|c|c|c|c|}
\cline { 2 - 10 } \multicolumn{1}{c|}{} & A1_1 & A2_1 & A3_1 & A4_1 & A5_1 & A6_1 & A7_1 & A8_1 & A9_1 & A10_1 \\
\hline Arithmetic Average & 1.263 & 4.073 & 4.970 & 6.243 & 3.700 & 2.903 & 3.517 & 3.367 & 2.313 & 3.633 \\
\hline Standart Deviation & 0.355 & 0.240 & 0.569 & 0.380 & 0.104 & 0.551 & 0.125 & 0.447 & 0.228 & 0.242 \\
\hline & A1_2 & A2_2 & A3_2 & A4_2 & A5_2 & A6_2 & A7_2 & A8_2 & A9_2 & A10_2 \\
\hline Arithmetic Average & 0.750 & 3.333 & 4.760 & 4.580 & 4.673 & 6.183 & 3.887 & 1.703 & 4.030 & 2.123 \\
\hline Standart Deviation & 0.075 & 0.254 & 0.337 & 0.216 & 0.667 & 0.680 & 0.055 & 0.357 & 0.525 & 0.429 \\
\hline
\end{tabular}

\section{Evaluation of surface roughness}

The next series of graphs have yellow bars to show cutting speed for the grinding wheel from $30 \mathrm{~m} . \mathrm{s}^{-1}$ and grey bars show cutting speed for the grinding wheel from $40 \mathrm{~m} . \mathrm{s}^{-1}$. A light color is used for the first measurement and a dark color is used for verification of the grinding on new samples.

\subsection{Average arithmetic deviation analysis - Ra and Rz}

In the following fig. 5 roughness Ra depends on the infeed rate. The lowest value $\mathrm{Ra} 0.194 \pm 0.007 \mu \mathrm{m}$ was achieved with an infeed rate of $0.13 \mathrm{~mm} \cdot \mathrm{min}^{-1}$ and cutting speed of $30 \mathrm{~m} \cdot \mathrm{s}^{-1}$. During the verification process, a value of $\mathrm{Ra} 0.176 \pm 0.011 \mu \mathrm{m}$ was achieved. By adding the standard deviation to the first grinding and subtracting the standard deviation for the second grinding, the values are within their range. The highest value $\mathrm{Ra} 0.337 \pm 0.015$ $\mu \mathrm{m}$ was achieved with an infeed rate of $0.64 \mathrm{~mm} \cdot \mathrm{min}^{-1}$ and cutting speed of $30 \mathrm{~mm} \cdot \mathrm{s}^{-1}$. Verification using these settings resulted in a value of $\mathrm{Ra} 0.331 \pm 0.010 \mu \mathrm{m}$. By subtracting the standard deviation for the first grinding and adding for the second grinding, the values are within their range. Looking at table 3 , it can be seen that values with a cutting speed of $40 \mathrm{~m} . \mathrm{s}^{-1}$ were increased about 5 $20 \%$. The biggest change or increase occurred at a feed rate of $0.17 \mathrm{~mm} \cdot \mathrm{min}^{-1}$.

Fig 6. shows the dependence of surface rougness Rz on infeed rate. This parameter Rz has very similar dependence as parameter $\mathrm{Ra}$. The parameter $\mathrm{Rz}$ shows the maximum and minuimum height of the protrusion in the measured length 1r. The lowest value was achieved for sample no. A1, where an infeed rate of $0.13 \mathrm{~mm} \cdot \mathrm{min}^{-1}$ and cutting speed of $30 \mathrm{~mm} . \mathrm{s}^{-1}$ were used. The result was $\mathrm{Rz}$ $1.418 \pm 0.061 \mu \mathrm{m}$. For cutting speed $30 \mathrm{~mm} . \mathrm{s}^{-1}$ an increasing infeed rate is seen, with values increasing about 0.140 $-0.250 \mu \mathrm{m}$ for each increase of infeed rate. Using a cutting speed of $40 \mathrm{~mm} . \mathrm{s}^{-1}$ the same rise in values is seen, with the difference that the values were $5-10 \%$ larger with the comparison of the reduced cutting speed of 30 $\mathrm{mm} . \mathrm{s}^{-1}$. The biggest change is seen with a cutting speed of $40 \mathrm{~mm} \cdot \mathrm{s}^{-1}$ and infeed rate of $0.41 \mathrm{~mm} \cdot \mathrm{min}^{-1}$, where value increased more than $0.4 \mu \mathrm{m}$.

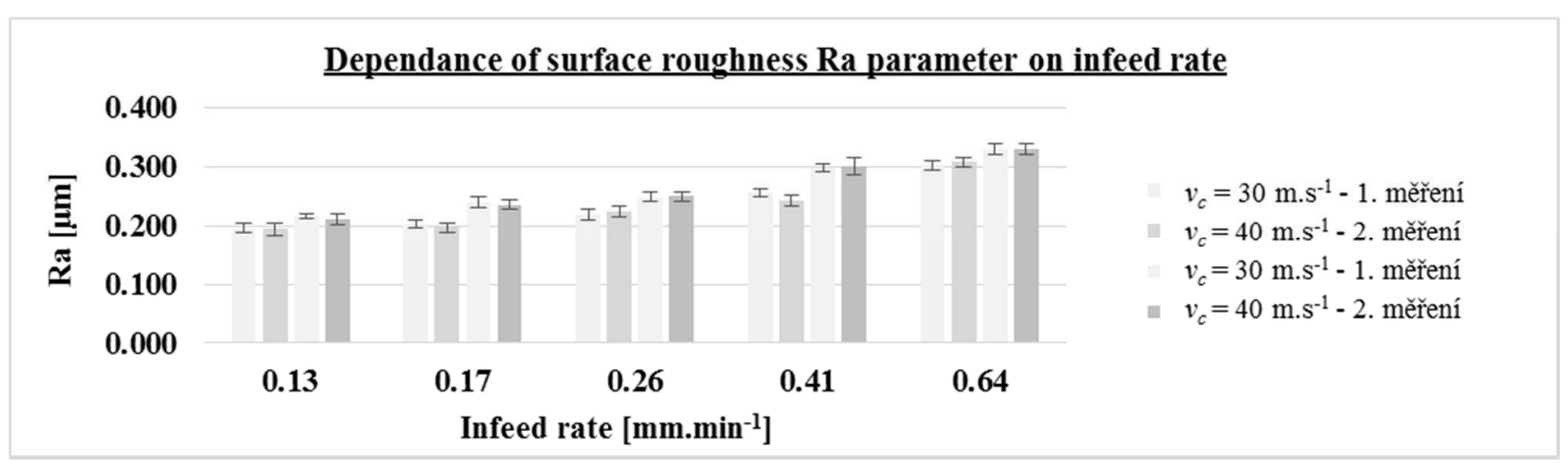

Fig. 5 The average value $R a$

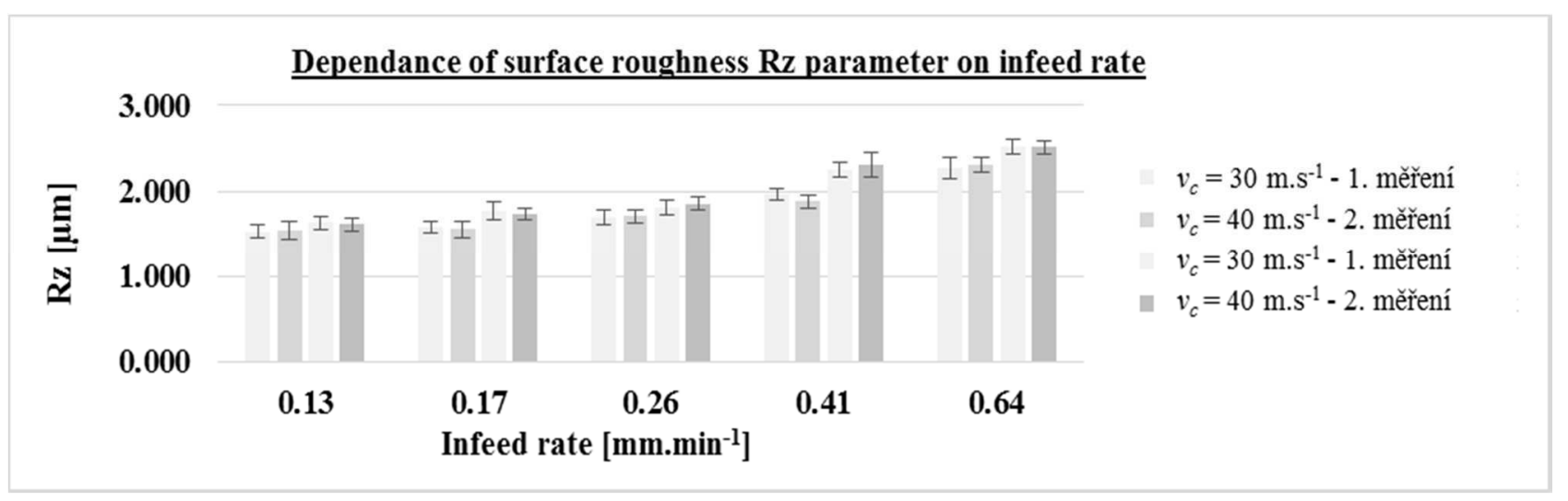

Fig. 6 The average value $R z$ 


\subsection{Average arithmetic deviation analysis - Rt}

The parameter Rt is very similar to Rz, also the sum of $\mathrm{Rp}$ and $\mathrm{Rv}$, the difference lies in the evaluated length ln. Fig. 7 shows the relationship between infeed rate and results of Rt. Increasing the infeed rate of the grinding wheel as in the previous measurements, where the values are also increasing. The highest and lowest values are the same as in the previous graphs in Figures 5 and 6. Here, when determining the standard deviations, it can be seen that the verification grinding No. 2 is within the range of the first grinding values. Also, the magnitude of the standard deviations is at very low levels, and up to $15 \%$.

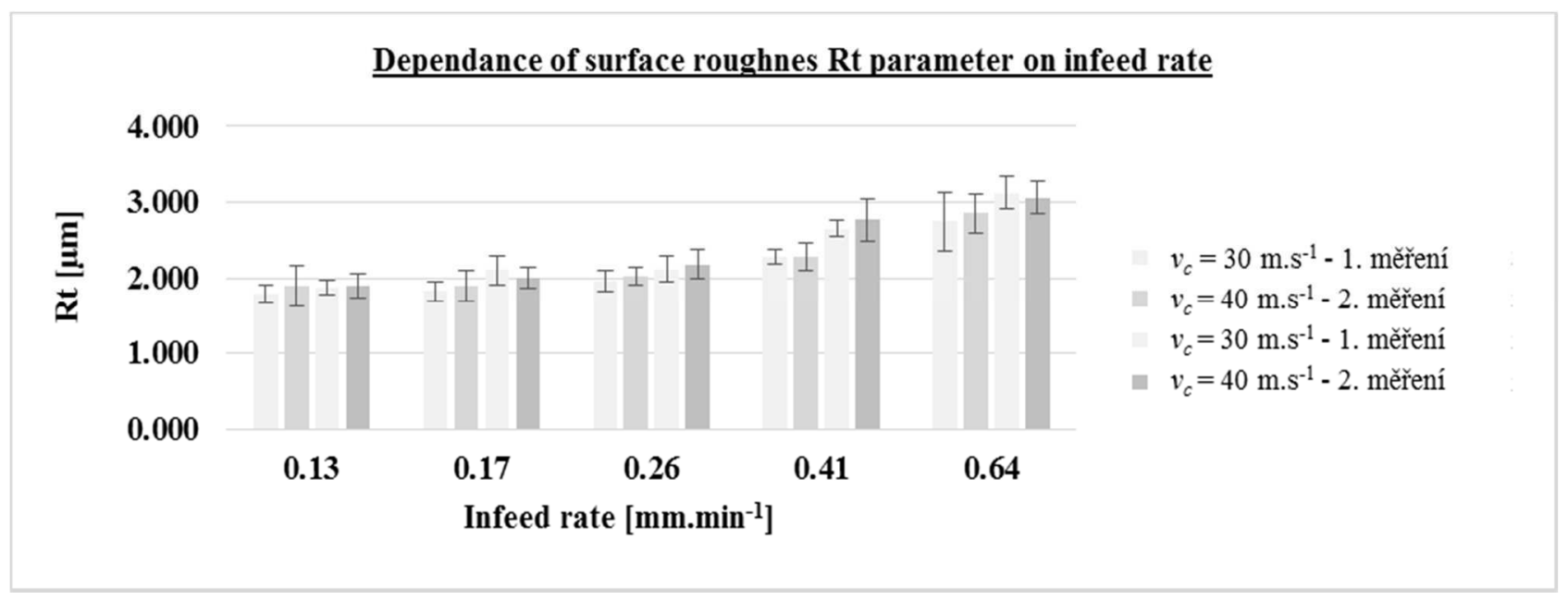

Fig. 7 The average value $R t$

\subsection{Average arithmetic deviation analysis - Rmax}

Another parameter to be studied is Rmax. This parameter Rmax is the sum of the maximum depth value and the highest peak in the range of five fundamental lengths. The values of parameter $\mathrm{Rz}$ are at the same rate for infeed rates of $0.13 ; 0.17 ; 0.26 \mathrm{~mm} . \mathrm{min}^{-1}$ and cutting speeds of 30 and $40 \mathrm{~m} \cdot \mathrm{s}^{-1}$. A more pronounced increase was at a cutting speed of $40 \mathrm{~m} . \mathrm{s}^{-1}$ with an infeed rate of 0.41 mm. min $^{-1}$ and a cutting speed of 30 and $40 \mathrm{~m} \cdot \mathrm{s}^{-1}$ with an infeed rate of $0.64 \mathrm{~mm} \cdot \mathrm{min}^{-1}$.

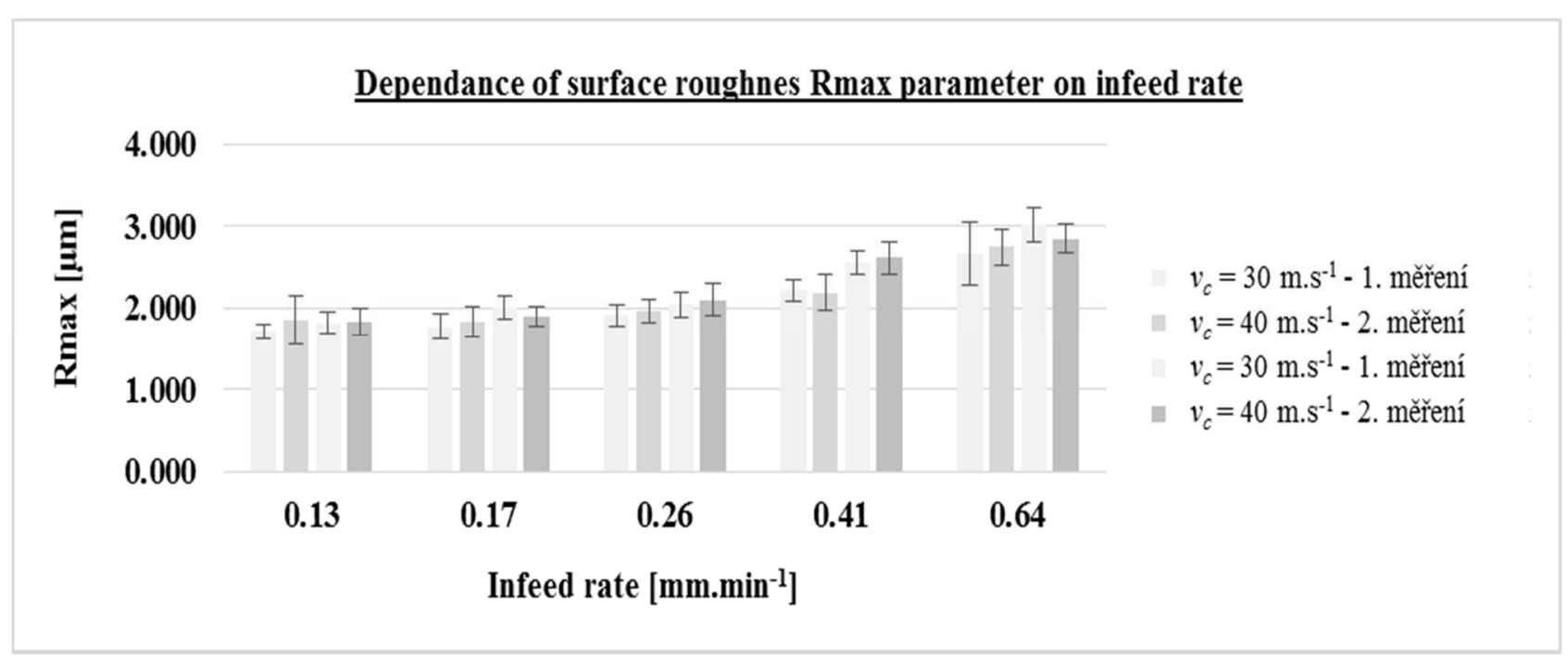

Fig. 8 The average value Rmax

\subsection{Average arithmetic deviation analysis - Rpk and Rvk}

Analysis of material ration curve shows a substantial influence on the functional characteristics of the component, where the size and quantity of peaks and valleys can be seen, because sometimes it is a good idea to have some peaks in the material and sometimes valleys. It depends on where components are used. Table 3 shows values for valleys and peaks. All A1 - A10 samples have larger valleys than peaks in their profile. The valleys are approximately $15-25 \%$ larger than the peaks. Lower values were achieved at lower infeed rates. At a cutting speed of $40 \mathrm{~m} \cdot \mathrm{s}^{-1}$ and feed rates of $0.13 \mathrm{~mm} \cdot \mathrm{min}^{-1}$ and 0.26 $\mathrm{mm} \cdot \mathrm{min}^{-1}$, the Rvk parameter values are lower than at a cutting speed of $30 \mathrm{~m} \cdot \mathrm{s}^{-1}$ by approximately $5-10 \%$. 


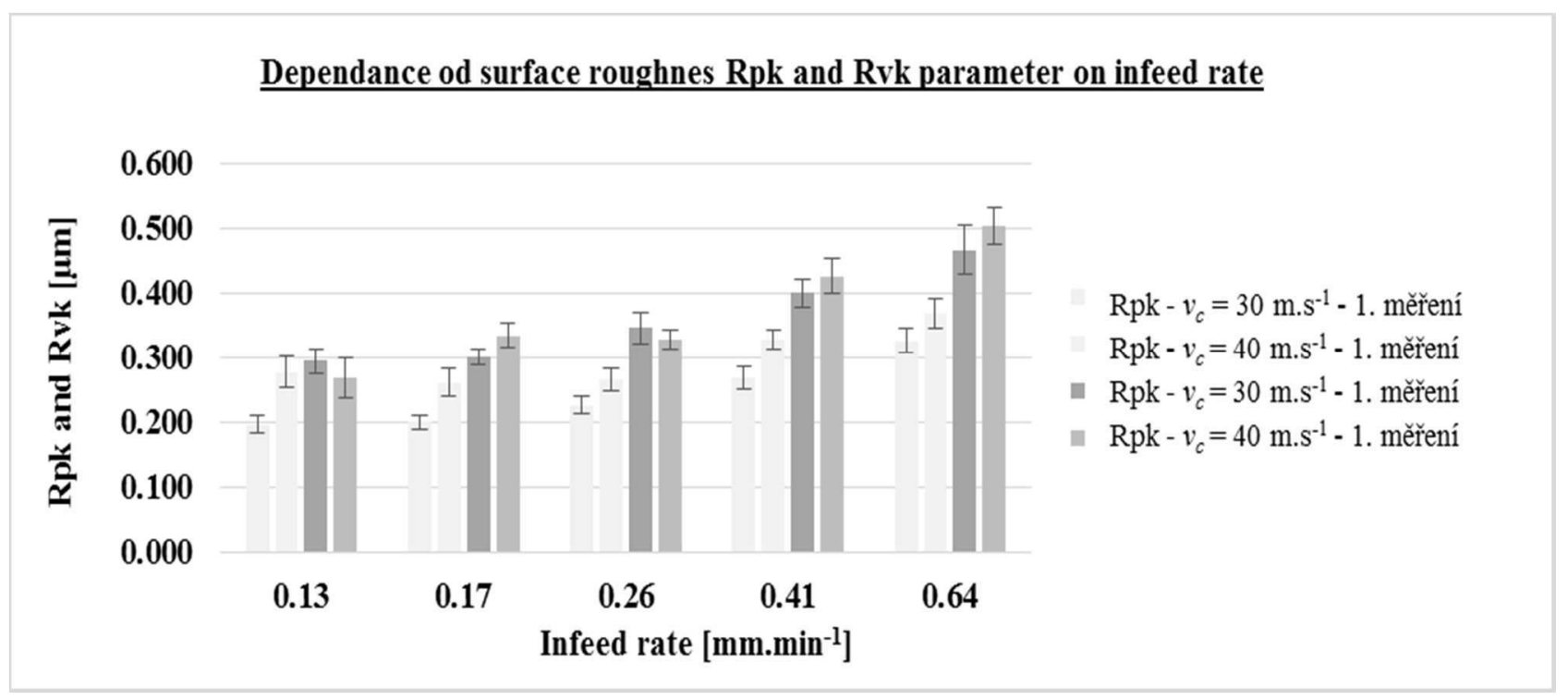

Fig. 9 The average value Rpk and Rvk

\subsection{Analysis of surface profile}

The material share curve (Abbott Firestone curve) is another integral parameter that characterizes the surface and is particularly important for dynamically loaded components. The basic purpose of the curve is the assessment of stressed functional surfaces and the solution of friction and lubrication issues. Its shape will vary depending on the surface quality. The more the curve takes the plane character, the more we can assume that the surface will exhibit lower roughness parameters. Figure 10 shows the material portions for a cutting speed of $30 \mathrm{~m} \cdot \mathrm{s}^{-1}$ and $3 \mathrm{di}-$ fferent infeed rates. All three surface topologies of infeed rates $0.13 ; 0.26 ; 0.64 \mathrm{~mm} . \mathrm{min}^{-1}$ are the same, only the size of the values are different. This curve shape shows a large fill of material with occasional longer recesses. In Fig. 11, for a cutting speed of $40 \mathrm{~m} \cdot \mathrm{s}^{-1}$ and the some infeed rates, the curve position was reduced. This has the significant percentage compensation represented in the material.
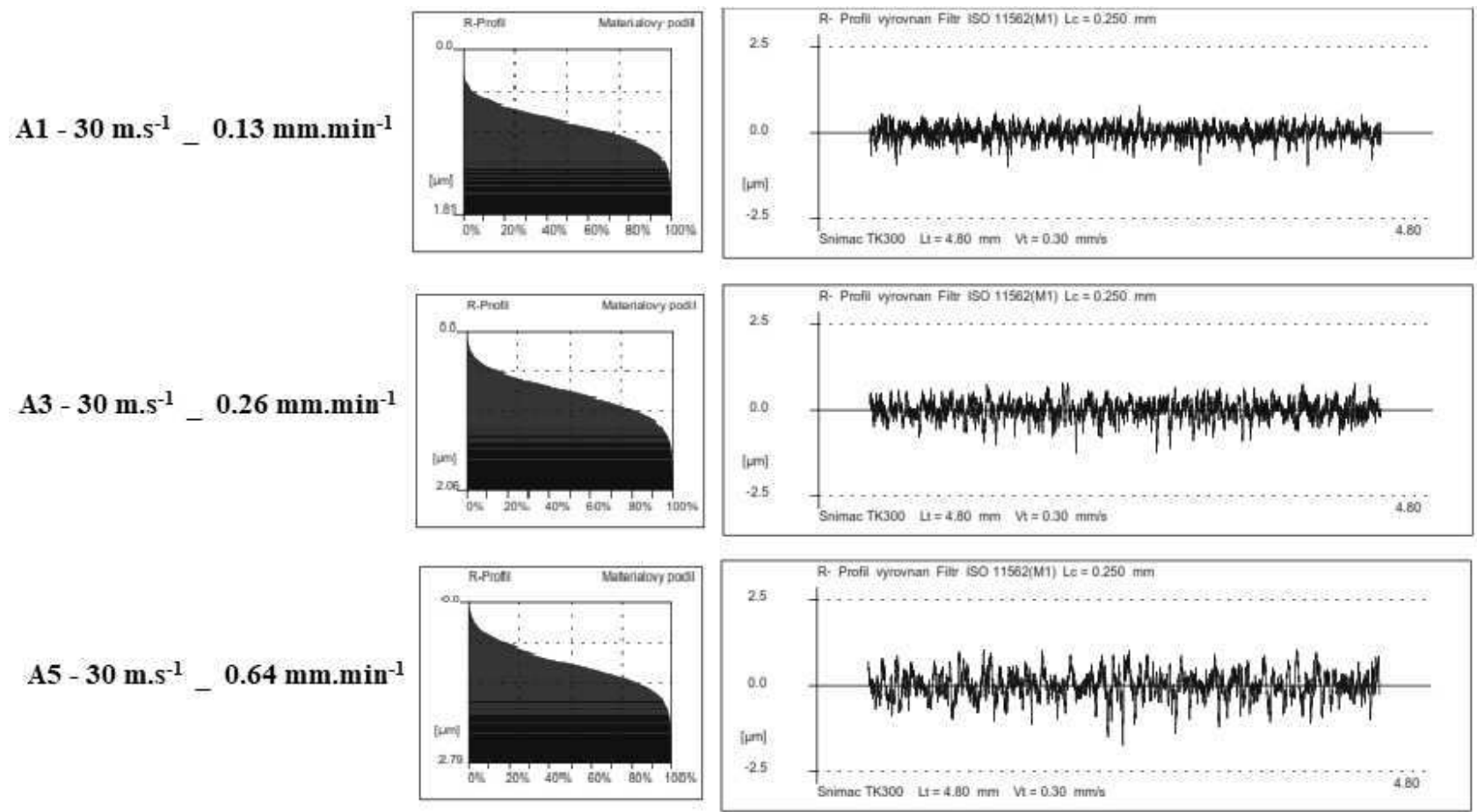

Fig. 10 The surface profile $30 \mathrm{~m} \cdot \mathrm{s}^{-1}$ 

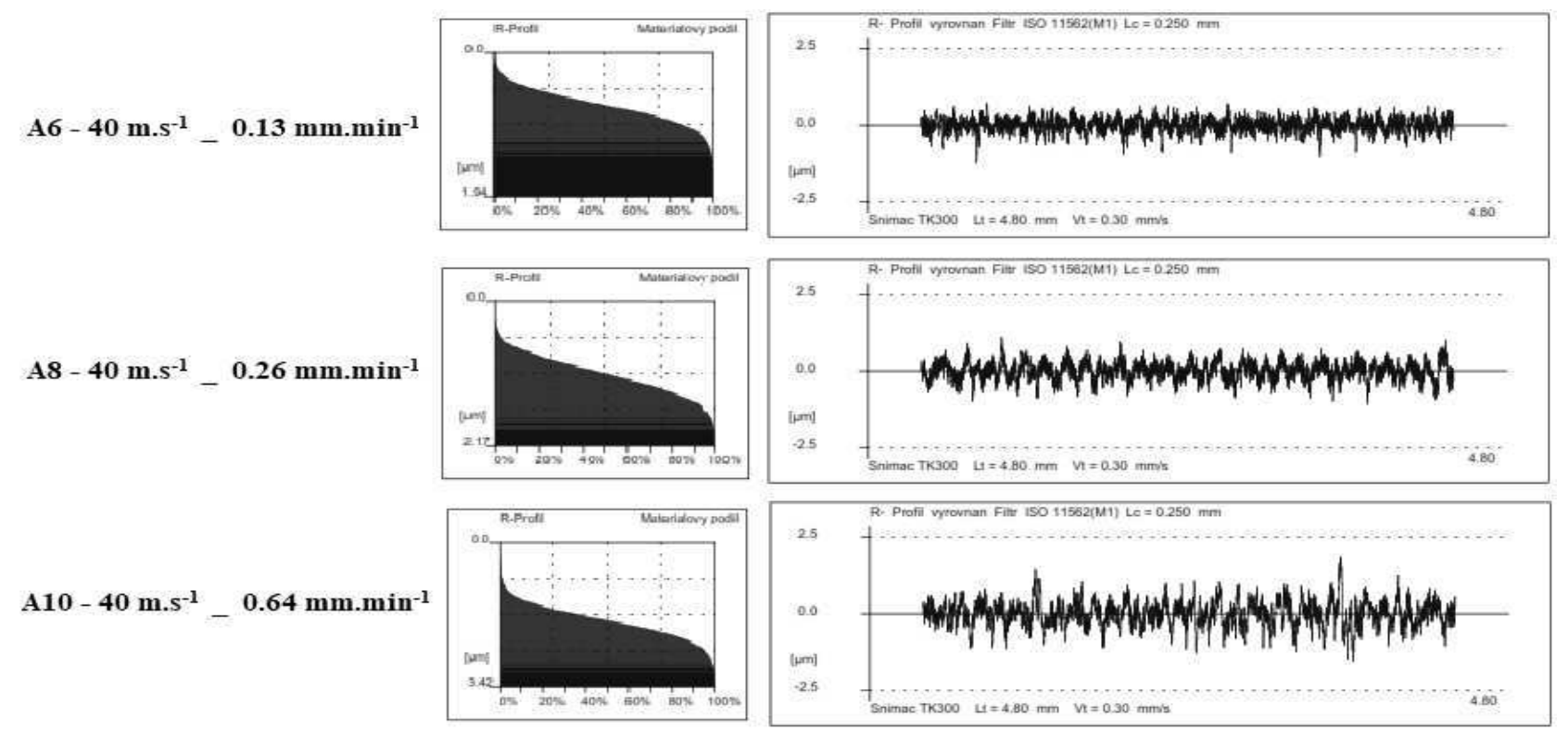

Fig. 11 The surface profile $40 \mathrm{~m} \cdot \mathrm{s}^{-1}$

\subsection{Analysis of circularity}

The circularity of two cutting speeds and five infeed rates is shown on figure 12. All values were supplemented by standard deviations. The curve is not the same as the roughness of the surface. For each cutting speed and feed rate, two samples were used, so two measurements were used to compare the measured results. For a cutting speed of $30 \mathrm{~m} . \mathrm{s}^{-1}$, the lowest $\mathrm{E}$ value was $1.263 \pm 0.355$ $\mu \mathrm{m}$ at a feed rate of $0.13 \mathrm{~mm} \cdot \mathrm{min}^{-1}$. By increasing the infeed velocity, the circularity values increased to the last infeed rate of $0.64 \mathrm{~mm} \cdot \mathrm{min}^{-1}$, where the value slightly decreased. The highest circularity $\mathrm{E}$ of $6.243 \pm 0.380 \mu \mathrm{m}$ was measured at a feed rate of $0.42 \mathrm{~mm} . \mathrm{min}^{-1}$. The second measurement verified $80 \%$ of the first measurement. For a $40 \mathrm{~m} . \mathrm{s}^{-1}$ cutting speed, the resulting values are unsatisfactory, because one measurement is very different from the test series. For example, at the lowest infeed rate of $0.13 \mathrm{~mm} \cdot \mathrm{min}^{-1}$, the values changed by almost $100 \%$. Overall, all measured results have a larger range of standard deviations. This phenomenon of divergent values could result, for example, in insufficient sample clamping, insufficient balancing, or oscillation of the SNOP system.

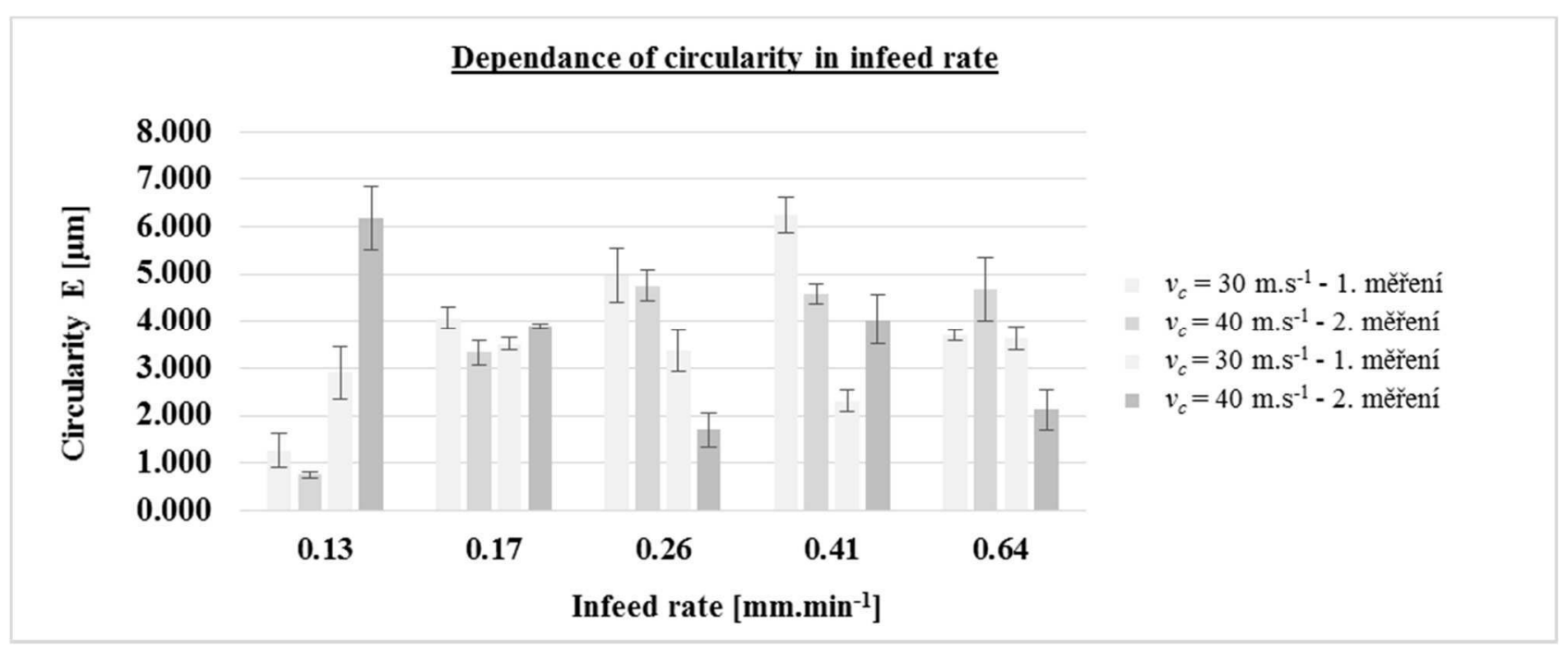

Fig. 12 Dependance of circularity

\section{Summary}

This experiment offers an explanation of changing cutting conditions on surface integrity after chrome plate grinding by microcrystalline corundum. For this experiment a total of 20 samples were tested, where 10 samples were used for the first measurement and the second 10 samples for the verification process. Cutting conditions were set to indicate the dependence of changing the cutting conditions on surface roughness and circularity. Extensive analysis of roughness parameters was due to the qualitatively rated new supplier for chrome plating and the use of new cutting conditions at grinding. The lowest values of surface rougness of Ra paramter for cutting speed of $30 \mathrm{~m} . \mathrm{s}^{-1}$ were achieved with an infeed 
rate of $0.13 \mathrm{~mm} \cdot \mathrm{min}^{-1}$, where the value of surface roughness was Ra $0.194 \pm 0.007 \mu \mathrm{m}$. With a cutting speed of $40 \mathrm{~m} . \mathrm{s}-1$ and infeed rate $0.13 \mathrm{~m} . \mathrm{min}^{-1}$, a surface roughness of Ra $0.268 \pm 0.015 \mu \mathrm{m}$ was achieved. The highest values were achieved with cutting speeds of $30 ; 40 \mathrm{~m} . \mathrm{s}^{-1}$ and infeed rate of $0.64 \mathrm{~mm} . \mathrm{min}^{-1}$, where the values were Ra $0.424 \pm 0.017 \mu \mathrm{m}$ and Ra $0.453 \pm 0.014 \mu \mathrm{m}$. All measured parameters as Rz, Rt, Rmax and Rq have the same dependence as $\mathrm{Ra}$, with increased infeed rates, surface roughness values were increased. During analysis of surface profiles it was seen that for all samples A1 - A10 there were larger valleys than peaks in their profile. The valleys were approximately $15-25 \%$ larger than the peaks. Lower values were achieved at lower infeed rates. By focusing on circularity, it can be seen that results have almost no dependence, because the values have diferent sizes and standard deviations are also of higher dimensions.

\section{Acknowledgement}

This project was supported by Solar Turbines EAME Ltd., and under project UJEP-SGS-2017-48-002-2.

\section{References}

[1] MÁDL. J.. KAFKA. J.. VRABEC. M.. DVOŘÁK. R. (2000). Technologie obrábění. 3. díl. Praha: ČVUT. 2000. 81 s.

[2] G. E. DIETER. (1989). Mechanical Metallurgy. McGraw Hill Higher Education. 1989.

[3] L. JIANG. J. PARO. H. HÄNNINEN. V. KAUPPINEN AND R. ORASKARI. (1996). Comparison of grindability of HIP austenitic 316L. duplex 2205 and Super duplex 2507 and ascast 304 stainless steels using alumina wheels. Journal of Materials Processing Technology. vol. 62. pp. 1- 9. 1996.

[4] MAREK, M., NOVÁK, M. (2017). The Effect of Changes in Feed Rate on Surface Integrity during Nickel Coating Grinding, Solid State Phenomena, Vol. 261, pp. 207-214, 2017

[5] NOVAK, M., NAPRSTKOVA, N. (2015). Grinding of the Alloy INCONEL 718 and Final oughness of the Surface and Material Share. In: $M a-$ nufacturing Technology, Vol. 15, No. 6 (2015) pp 1015-1023, ISSN: 1213-2489.

[6] MAREK. M.. NOVÁK. M. (2016). Hodnocení drsnosti povrchu po broušení niklového povlaku při změně řezných podmínek. Strojírenská Technologie. 2016. ročník XXI. číslo 1. s. 33-38. ISSN $1211-4162$

[7] MARINESCU. Z.. D.. aj. (2007). Handbook of machining with grinding wheels. Boca Raton : CRC Press.2007. 592 s. ISBN 1-57444-671-1

[8] M.R KALANTARY. K.A HOLBROOK. P.B WELLS. (1993). Trans. Instut. Metal Finishing. 71 (2) (1993). p. 55

[9] MAREK, M., NOVÁK, M., HOLESOVSKY, F., DURAKBASA, M., N. (2017). The Effect of Changes to Nickel Coating Machine on Surface Integrity and Microstructure after Grinding, In: Manufacturing Technology, Vol. 17, No. 6 (2017) pp 906-912, ISSN: 1213-2489.

[10] M. FIELD AND J. KAHLES. (1964). The surface integrity of machined and ground high strength steels. pp. 210: 54-77. 1964.

[11] MAREK. M.. NOVÁK. M. (2017). The Effect of Changes in Feed Rate on Surface Integrity during Nickel Coating Grinding. Solid State Phenomena. Vol. 261. pp. 207-214. 2017

[12] MADL. J. (2001). Theoretival aspect of precise machining. In I. International Congress of precision machining. Ústí nad labem. Czech Republic : ÚTŘV. J. E. Purkyne University. 2001. s 65-69. ISBN 80-7044-358-8

[13] MAREK. M.. NOVÁK. M.. RYTINA. T.. DURAKBASA. M.. N. (2017). Process and Equipment Improvement for Nickel Brush Plating Application. In: Manufacturing Technology. Vol. 17. No. 4 (2017) pp 503-507. ISSN: 1213-2489

[14] Tvrdé chromování. BOMEX CZ. Bomex [online]. 1999 [cit. 2012-04-18]. Dostupné z: http://www.bomex.cz/cz/3-technologie/8-tvrdechromovani.html

[15] JINFENG ZHANG, CHAO FENG, YUNHUI MA, WEI TANG, SHUAI WANG, XIN ZHONG. (2017). Nondestructive analysis of surface integrity in turning and grinding operations In: Manufacturing Technology, Vol. 17, No. 3, pp. 412-418, ISSN:1213-2489.

[16] MALlORY. G. O. a J. B. HAJDU. (1990). Electroplaters and Surface Finishers Society. Electroless plating: fundamentals and applications, Society, Orlando, Fla. 1990. 539pp. ISBN 978-0815512776 